\begin{tabular}{l|ll} 
J B E & $\mid \begin{array}{ll}\text { JOURNAL OF } \\
\text { BIOLOGY }\end{array}$ & $\begin{array}{l}\text { E-ISSN 2656-3436/ P-ISSN 2615-3947 } \\
\text { IAIN KUDUS } \\
\text { Tersedia online: http://journal.iainkudus.ac.id/index.php/jbe }\end{array}$ \\
\hline
\end{tabular}

\title{
Analisis Potensi Hasil Penelitian Etnobotani Tradisi Kuthomoro di Makam Giriloyo Imogiri Bantul Yogyakarta sebagai Sumber Belajar Biologi SMA
}

\author{
Nida Dwi Handayani ${ }^{1}$,Hendro Kusumo Eko Prasetyo Moro ${ }^{2}$ \\ Pendidikan Biologi Universitas Ahmad Dahlan 1,2 \\ nidadwi9@gmail.com ${ }^{1}$, hendro.kusumo@pbio.uad.ac.id ${ }^{2}$
}

\begin{abstract}
ABSTRAK
Belum ada penelitian pendidikan yang mengangkat etnobotani sebagai sumber belajar siswa SMA kelas X materi tumbuhan di SMA Negeri 1 Imogiri. Penelitian ini bertujuan untuk mengetahui jenis tumbuhan dan makna simbolik yang digunakan dalam Tradisi Kuthomoro di Makam Giriloyo, serta mengetahui potensi sumber belajar materi Tumbuhan SMA kelas $\mathrm{X}$ pada tradisi tersebut. Penelitian ini merupakan jenis penelitian kualitatif. Subjek dalam penelitian ini yaitu Abdi Dalem Juru Kunci. Objek dalam penelitian ini ialah tumbuhan yang digunakan dalam kegiatan Tradisi Kuthomoro di Makam Giriloyo. Teknik pengumpulan data yaitu observasi, wawancara mendalam, dan dokumentasi. Instrumen yang digunakan adalah pedoman wawancara, lembar observasi, dan daftar dokumen. Teknik analisis data menggunakan analisis deskriptif. Hasil penelitian memperlihatkan terdapat 44 jenis tumbuhan yang digunakan pada uborampe bunga dan sajian dalam tradisi. Makna simbolik dari tumbuhan yang digunakan pada tradisi tersebut ialah sebuah doa dan harapan baik semoga kesalahan para leluhur dimaafkan dan diberi tempat yang lebih baik oleh Allah SWT. Berdasarkan analisis potensi sumber belajar, hasil penelitian ini berpotensi sebagai sumber belajar biologi SMA kelas X materi tumbuhan pada divisi Spermatophyta.
\end{abstract}

Kata kunci: Etnobotani, Sumber Belajar, Tradisi Kuthomoro. 


\begin{abstract}
There is no educational research that raises ethnobotany as a learning resource for class $X$ high school students on plant material at SMA Negeri 1 Imogiri. This study aims to determine the types of plants and the symbolic meanings used in the Kuthomoro Tradition in the Giriloyo Tomb, as well as to determine the potential learning resources of Class X Senior High School Plant material in the tradition. This research is a type of qualitative research. The subjects in this study were Abdi Dalem Juru Kunci. The object of this research is the plants used in the Kuthomoro Tradition activities at the Giriloyo Tomb. Data collection techniques are observation, in-depth interviews, and documents. The instruments used were interview guides, observation sheets, and a list of documents. The data analysis technique used descriptive analysis. The results showed that there were 44 types of plants used in flower uborampe and traditional dishes. The symbolic meaning of plants used in this tradition is a prayer and good wishes that the mistakes of the ancestors are forgiven and given a better place by Allah SWT. Based on the analysis of potential learning resources, the results of this study have the potential to be a source of learning biology in high school class X plant material in the Spermatophyta division.
\end{abstract}

Keywords: Ethnobotany, Learning Resources, Kuthomoro Tradition.

\title{
PENDAHULUAN
}

Yogyakarta merupakan salah satu Kota di Pulau Jawa yang memiliki keistimewaan tersendiri di Indonesia. Pemerintahan Yogyakarta dipimpin oleh Kerajaan Ngayogyakarta Hadiningrat, di mana kerajaan tersebut masih mempertahankan nilai kearifan lokal yang memiliki nilai-nilai leluhur secara turun-temurun hingga sampai saat ini. Yogyakarta merupakan kota budaya yang mana masyarakatnya masih menjaga dan melestarikan kebudayaan lokal maupun kebudayaan Nusantara. Salah satu wujud dari kebudayaan tersebut dengan adanya tradisi yang dilaksanakan secara turun-temurun yaitu Tradisi Kuthomoro. Kuthomoro merupakan salah satu tradisi yang dilaksanakan di Makam Giriloyo, Dusun Cengkehan, Desa Wukirsari, Kecamatan Imogiri, Bantul, Yogyakarta. Tradisi Kuthomoro di Makam Giriloyo yang dimaksud yaitu utusan dari kraton mengirim uborampe untuk melaksanakan kegiatan Nyadran Dalem.

Tradisi Kuthomoro di Makam Giriloyo dilaksanakan pada bulan Ruwah atau biasanya disebut bulan Sya'ban dalam kalender Hijriyah sebelum menjelang bulan Puasa Ramadhan. Tradisi Kuthomoro dilakukan khusus oleh para Abdi Dalem Juru Kunci. Adapun kegiatan yang dilakukan yaitu berdoa, tabur bunga dan bedah tumpeng di Makam para leluhur Giriloyo. Para leluhur yang telah dikebumikan di Makam Giriloyo antara lain Kanjeng Ratu 
Pembayun (Istri Sunan Amangkurat I), Kanjeng Ratu Mas Hadi (ibunda Sultan Agung), Kanjeng Panembahan Juminah (paman Sultan Agung), Kiai Ageng Giring, Kiai Ageng Sentong dan Sultan Cirebon V yang diikuti oleh beberapa tokoh lainnya.

Berdasarkan survei pendahuluan, dalam Tradisi Kuthomoro menggunakan uborampe untuk dijadikan pelengkap tradisi. Uborampe yang digunakan meliputi bunga, sesaji dan bahan pelengkap lainnya. Uborampe memanfaatkan beberapa jenis tumbuhan. Tumbuhan yang digunakan dalam uborampe Tradisi Kuthomoro memiliki makna simbolik tersendiri tetapi belum diketahui maknanya oleh masyarakat.

Kajian etnobotani ini akan memberikan gambaran prosesi Tradisi Kuthomoro di masyarakat Jawa khususnya di Makam Giriloyo. Etnobotani merupakan ilmu yang mempelajari hubungan antara etnik-etnik (kebudayaan) tertentu dengan tumbuhan di sekitarnya yang dimanfaatkan secara turun-temurun. Berdasarkan hal tersebut, untuk melestarikan kearifan lokal maka Pemerintah menetapkan Peraturan Daerah Provinsi Daerah Istimewa Yogyakarta nomor 5 Tahun 2011 tentang Pengelolaan dan Penyelenggaraan Pendidikan Berbasis Budaya. Pendidikan berbasis budaya adalah pendidikan yang diselenggarakan untuk memenuhi standar nasional pendidikan yang diperkaya dengan keunggulan komparatif dan kompetitif berdasar nilai-nilai luhur budaya agar siswa secara aktif dapat mengembangkan potensi diri sehingga menjadi manusia yang unggul, cerdas, visioner, peka terhadap lingkungan dan keberagaman budaya, serta tanggap terhadap perkembangan dunia. Satuan pendidikan berbasis budaya adalah kelompok layanan pendidikan yang menyelenggarakan pendidikan pada jalur formal, nonformal, dan informal pada setiap jenjang dan jenis pendidikan dengan mengedepankan nilai-nilai luhur budaya.

Tumbuhan yang digunakan dalam prosesi Tradisi Kuthomoro di Makam Giriloyo akan dianalisis potensinya sebagai alternatif sumber belajar dalam pembelajaran biologi yang menarik karena tidak semua memahami makna simbolik penggunaan tumbuhan tersebut, hanya beberapa tumbuhan yang diketahui maknanya. Berdasarkan kurikulum 2013, salah satu Kompetensi Dasar (KD) yang harus dikuasai oleh siswa SMA kelas X adalah KD 3.8 mengelompokkan tumbuhan ke dalam divisi berdasarkan ciri-ciri umum, serta mengaitkan peranannya dalam kehidupan. Materi yang harus dikuasai adalah tumbuhan. 
Berdasarkan hasil wawancara dengan guru Biologi kelas X SMAN 1 Imogiri bahwa belum adanya pemanfaatan lingkungan sekitar sekolah khususnya di Daerah Makam Giriloyo Imogiri Bantul sebagai sumber belajar biologi SMA, sehingga diperlukan hasil penelitian etnobotani Tradisi Kuthomoro di Makam Giriloyo untuk menambah pengetahuan dan informasi bagi siswa. Pada proses pembelajaran biologi guru menggunakan buku ajar dan memanfaatkan lingkungan sekolah sebagai sumber belajar.

Berdasarkan penelitian yang terdahulu, penelitian yang telah dilakukan di Daerah Giriloyo ialah penelitian oleh Arisandi (2013) terkait Tradisi Adzan Tumbal di Dusun Giriloyo Desa Wukirsari Kecamatan Imogiri Kabupaten Bantul Yogyakarta dan penelitian oleh Ningsih (2012) terkait Nilai-Nilai Pendidkan Islam dalam Tradisi Rasulan di Desa Giriloyo, Wukirsai, Imogiri, Bantul. Berdasarkan dua penelitian tersebut belum mengaitkan antara tradisi yang ada di Giriloyo dengan pembelajaran biologi SMA di sekolah sekitar. Belum adanya penelitian terkait Tradisi Kuthomoro di Makam Giriloyo sebagai sumber belajar biologi SMA muncul ketertarikan penulis untuk melakukan penelitian.

Penelitian ini penting dilakukan dengan mengambil judul Analisis Potensi Sumber Belajar Hasil Penelitian Etnobotani Tradisi Kuthomoro di Makam Giriloyo Imogiri Bantul Yogyakarta sebagai Materi Biologi SMA. Oleh karena itu, guru perlu mengembangkan etnobotani kedalam pendidikan berbasis budaya untuk diterapkan kepada siswa sesuai dengan adanya kurikulum pendidikan berbasis budaya. Hal tersebut diterapkan agar siswa mampu mengetahui budaya yang telah ada dimasyarakat yang sudah turun-temurun. Dalam praktiknya menerapkan kurikulum pendidikan berbasis budaya masih sulit terpenuhi apabila hanya menggunakan sumber belajar berupa buku pelajaran yang tersedia, oleh karena itu diperlukan alternatif sumber belajar dari etnobotani Tradisi Kuthomoro di Makam Giriloyo. Penelitian ini bertujuan untuk mengetahui pelaksanaan Tradisi Kuthomoro di Makam Giriloyo dan mengetahui jenis-jenis tumbuhan serta makna simboliknya.

\section{METODE}

Penelitian ini merupakan penelitian kualitatif. Penelitian kualitatif merupakan penelitian yang digunakan untuk mendeskripsikan dan menganalisis fenomena, peristiwa, aktifitas sosial, kepercayaan, presepsi, dan orang secara individual maupun kelompok (Sukmadinata, 2009). Penelitian dilakukan di Makam Giriloyo yang terletak di arah Selatan 
Kraton Yogyakarta, tepatnya di Wilayah Dusun Cengkehan, Desa Wukirsari, Kecamatan Imogiri, Bantul, Provinsi Daerah Istimewa Yogyakarta. Waktu penelitian dari tanggal 25 Oktober 2019 - 02 November 2020.

Prosedur penelitian menggunakan tiga tahap yaitu pra-lapangan, penelitian lapangan, dan pasca penelitian. Tahap pra-lapangan ini merupakan tahap dimana penelitian harus mempertimbangkan etika penelitian dengan cara melakukan beberapa tahap yaitu menyusun rancangan, memilih lapangan penelitian, membuat surat izin untuk melakukan penelitian, menjajaki dan menilai lapangan, memilih dan memanfaatkan informan, menyiapkan perlengkapan penelitian dengan membuat surat izin penelitian, instrumen observasi dan instrumen wawancara yang sudah divalidasi. Tahap penelitian lapangan ini hal yang harus dilakukan ada 3 bagian yaitu memahami latar belakang penelitian dan persiapan diri, memasuki lapangan, dan berperan serta sambil mengumpulkan data. Tahap pasca penelitian berupa analisis hasil. Analisis hasil ini merupakan kegiatan yang berupa mengolah data yang diperoleh dari dokumentasi dan hasil wawancara.

Analisis data pada penelitian ini dilakukan secara deskriptif. Analisis deskriptif merupakan analisis data untuk mendeskripsikan hasil data yang diperoleh selama dilakukan penelitian. Mengumpulkan data berdasarkan kelompoknya yaitu bunga-bunga dan sajian (tumbuhan) yang disiapkan atau digunakan pada Tradisi Kuthomoro di Makam Giriloyo, serta makna filosofinya. Berdasarkan hasil yang telah diperoleh, dilanjutkan dengan telaah potensi hasil penelitian sebagai alternatif sumber belajar Biologi SMA Kelas X materi tumbuhan divisi Spermatophyta.

\section{HASIL DAN PEMBAHASAN}

Tradisi Kuthomoro di Makam Giriloyo atau disebut juga tradisi Nyadran Dalem di Makam Giriloyo. Tradisi Kuthomoro dilakukan setiap satu tahun sekali di tanggal 15 Ruwah yang diikuti oleh para Abdi Dalam Juru Kunci. Tradisi Kuthomoro merupakan tradisi dari keraton. Tradisi Kuthomoro ini bertujuan untuk mengirim doa supaya kesalahan para leluhur dimaafkan dan diberi tempat yang lebih baik oleh Allah SWT.

Berdasarkan hasil penelitian terdapat 44 jenis tumbuhan yang digunakan pada Tradisi Kuthomoro di Makam Giriloyo yang berasal dari uborampe bunga-bunga dan sajian. Menurut Pranoto (2009) dalam kebudayaan Jawa, uborampe dijadikan sarana atau wadah 
yang dapat membawa dan menyampaikan ide-ide atau pandangan hidup masyarakat yang memiliki kebudayaan. Tumbuhan yang digunakan ialah Malus domestica Borkh., Allium ascalonicum L., Allium sativum L., Amaranthus hybridus L., Pachyrhizus erosus (L.) Urb., Capsicum annuum L., Capsicum frutescens L., Zingiber officinale Roscoe., Archidendron pauciflorum (Benth.) I.C.Nielsen., Citrus aurantium L., Citrus hystrix DC., Vigna radiata (L.) R.Wilczek., Vigna cylindrica (L.) Skeels, Arachis hypogaea L., Vigna unguiculata (L.) Walp., Ipomoea aquatica Forssk., Michelia alba DC., Glycine max (L.) Merr., Cocos nucifera L., Aleurites moluccanus (L.) Willd., Cananga odorata (Lam.) Hook.f. \& Thomson., Kaempferia galanga L., Coriandrum sativum L., Brassica oleracea L., Curcuma longa L., Alpinia galanga (L.) Willd., Rosa damascena Herrm., Rosa alba L., Jasminum sambac (L.) Aiton., Cucumis sativus L., Oryza sativa L., Pandanus amaryllifolius Roxb., Carica papaya L., Musa paradisiaca L., Salacca zalacca (Gaertn.) Voss, Syzygium polyanthum (Wight) Walp., Achras zapota L., Ocimum basilicum L., Cymbopogon citratus (DC.) Stapf., Manihot utilisima Pohl., Ipomoea batatas (L.) Lam., Bambusa sp., Tectona grandis L.f. dan Daucus carota L. Berdasarkan hasil analisis tumbuhan tersebut termasuk kedalam divisi Spermetophyta.

\section{Manfaat, cara dan makna jenis tumbuhan yang digunakan pada Tradisi Kuthomoro di Makam Giriloyo}

Tradisi Kuthomoro di Makam Giriloyo terdapat uborampe bunga-bunga dan sajian yang digunakan dan dipersiapkan. Pembahasan uborampe bunga-bunga dan sajian yang digunakan akan diuraikan sebagai berikut:

a. Bunga

Bunga yang digunakan pada Tradisi Kuthomoro di Makam Giriloyo ada 6 macam. Berdasarkan hasil penelitian bunga yang digunakan memiliki makna tersendiri yang akan diuraikan sebgagai berikut :

Tabel 1. Makna bunga dalam Tradisi Kuthomoro di Makam Giriloyo

\begin{tabular}{|c|c|c|}
\hline No & Jenis bunga & Makna \\
\hline & $\begin{array}{l}\text { Rosa damascena } \\
\text { Herrm. }\end{array}$ & $\begin{array}{l}\text { Makna mawar merah yaitu manusia memiliki hidup yang } \\
\text { berwarna-warna, diminta untuk jadi putih (suci) sulit, } \\
\text { sehingga menjadi merah (amarah) maka manusia harus } \\
\text { bertindak kebaikan. }\end{array}$ \\
\hline
\end{tabular}




\begin{tabular}{lll}
\hline 2. & Rosa alba L. & $\begin{array}{l}\text { Makna mawar putih yaitu rame ing gawe sepi ing pamrih } \\
\text { yang berarti manusia itu sebaiknya banyak berbuat } \\
\text { kebaikan namun tidak meminta balasan atau pamrih. }\end{array}$ \\
\hline 3. & $\begin{array}{l}\text { Jasminum sambac } \\
\text { (L.) Aiton. }\end{array}$ & $\begin{array}{l}\text { Melati berasal dari kata lathi yang berarti lidah, yang } \\
\text { berarti manusia kalau berucap baik buruknya akan } \\
\text { kembali pada dirinya. }\end{array}$ \\
\hline 4. & $\begin{array}{l}\text { Cananga odorata } \\
\text { (Lam.) Hook.f. \& } \\
\text { Thomson. }\end{array}$ & $\begin{array}{l}\text { Makna kenanga ialah untuk mengenang jasa manusia } \\
\text { yang sudah meninggal. }\end{array}$ \\
\hline 5. & Michelia alba DC. & $\begin{array}{l}\text { Makna kantil berasal dari kata kumantil-mantil yang } \\
\text { berarti untuk mengingat kepada orang yang sudah } \\
\text { meninggal. }\end{array}$ \\
& Ocimum basilicum & $\begin{array}{l}\text { Telasih berasal dari kata wes telas rasa asih yang berarti } \\
\text { sudah habis nikmat dan kasih sayang manusia yang telah } \\
\text { meninggal karena sudah menghadap Allah SWT. Manusia } \\
\text { yang sudah meninggal sudah tidak bisa menikmati apa- } \\
\text { apa kecuali amal kebaikannya. }\end{array}$ \\
\hline
\end{tabular}

Bunga-bunga tersebut dimanfaatkan untuk tabur bunga di atas makam para leluhur yang dipercayai oleh para Abdi Dalem Juru Kunci di Makam Giriloyo sebagai wasilah. Tabur bunga di atas makam memiliki makna bahwa manusia yang sudah meninggal akan diringankan dosanya dan dibebaskan dari siksa kubur sebelum bunga tersebut kering. Menurut para Abdi Dalem Juru kunci bunga-bunga tersebut dapat dijadikan wangian di makam karena bunga tersebut memiliki aroma wangi. Bunga-bunga yang digunakan dalam upacara adat umumnya memiliki aroma harum karena mengandung minyak atsiri yang bersifat mudah menguap (Supinah, 2006). Minyak atsiri pada tumbuhan dapat diperoleh dari berbagai bagian yaitu daun, bunga, buah, biji, kulit biji, batang dan rimpang (Rusli, 2010). Selain bunga dan sajian terdapat juga kemenyan madu, dupa, lilin, minyak wangi dan amplop yang berisi uang Rp. 10.000 yang digunakan sebagai pasangan bunga saat tradisi Kuthomoro di Makam Giriloyo.

b. Sajian

Sajian untuk tradisi Kuthomoro ini dimasak khusus oleh Abdi Dalem Putri Imogiri. Pada saat memasak para Abdi Dalem Putri harus dalam keadaan suci tidak sedang menstruasi. Sebelum memasak para Abdi Dalem Putri harus berwudhu terlebih dahulu supaya dalam keadaan suci. Memasak sajian tradisi harus wanita dalam keadaan suci, hal ini bertujuan untuk menyempurnakan sedekah pemilik hajat terlaksana dengan 
lancar. Kesucian dan kebersihan merupakan lambang manusia baik, karena Allah SWT menyukai manusia baik dan akan mengambulkan keinginannya (Puspita, 2018). Bahanbahan yang digunakan pada setiap sajian akan diuraikan pada tabel 2 .

Tabel 2. Bahan-bahan yang digunakan pada sajian tradisi Kuthomoro di Makam Giriloyo

\begin{tabular}{|c|c|c|}
\hline $\begin{array}{c}\text { Nama } \\
\text { Makanan }\end{array}$ & $\begin{array}{c}\text { Komponen } \\
\text { makanan }\end{array}$ & Bahan-bahan yang digunakan untuk membuat sajian \\
\hline \multirow[t]{10}{*}{$\begin{array}{l}\text { Sekul Suci } \\
\text { Ulamsari }\end{array}$} & $\begin{array}{l}\text { Nasi Uduk / } \\
\text { Nasi Gurih }\end{array}$ & $\begin{array}{l}\text { Nasi yang dimasak dengan santan kepala ditambah dengan } \\
\text { bawang merah dan garam }\end{array}$ \\
\hline & $\begin{array}{l}\text { Ingkung } \\
\text { ayam }\end{array}$ & $\begin{array}{l}\text { Satu ekor ayam jago/ayam jantan diberi bumbu bawang merah } \\
\text { iris, daun salam, gula merah dan garam. Lalu sebagian bumbu } \\
\text { di masukan kedalam perut ayam kemudian diikat dan } \\
\text { dimasukan panci ditambah air secukupnya kemudian direbus } \\
\text { selama } 2 \text { jam }\end{array}$ \\
\hline & Ketan & $\begin{array}{l}\text { Ketan dibuat dari beras ketan yang diberi bumbu dengan } \\
\text { santan kelapa dan garam kemudian ditanak sehingga rasanya } \\
\text { gurih dan lekat }\end{array}$ \\
\hline & Kolak & $\begin{array}{l}\text { Kolak dibuat dari ubi jalar/telo dan pisang mas kemudian } \\
\text { diberi bumbu gula merah dan garam }\end{array}$ \\
\hline & Apem & $\begin{array}{l}\text { Apem merupakan makanan yang terbuat dari tepung beras } \\
\text { yang dimasak dengan tape singkong serta sedikit garam } \\
\text { kemudian dicetak }\end{array}$ \\
\hline & Lalapan & $\begin{array}{l}\text { Lalapan yang digunakan ada kubis, mentimun, toge kacang } \\
\text { hijau dan jengkol }\end{array}$ \\
\hline & $\begin{array}{l}\text { Kedelai } \\
\text { goreng }\end{array}$ & Kedelai hitam digoreng \\
\hline & $\begin{array}{l}\text { Sambel } \\
\text { kacang } \\
\text { tanah }\end{array}$ & $\begin{array}{l}\text { Sambel kacang dibuat dari kacang tanah goreng ditumbuk dan } \\
\text { diberi bumbu cabe rawit, gula merah, kencur, daun jeruk purut } \\
\text { dan garam }\end{array}$ \\
\hline & Kerupuk & - \\
\hline & $\begin{array}{l}\text { Wajik } \\
\text { merah }\end{array}$ & $\begin{array}{l}\text { Wajik dibuat dari beras ketan yang dimasak kemudian } \\
\text { ditambahkan gula merah, daun pandan, santan, dan sediki } \\
\text { garam. }\end{array}$ \\
\hline \multirow[t]{4}{*}{$\begin{array}{l}\text { Tumpeng } \\
\text { kuning }\end{array}$} & Nasi kuning & $\begin{array}{l}\text { Nasi yang dimasak dengan santan kepala ditambah dengan } \\
\text { bawang merah, garam dan diberi warna kuning dari kunyit }\end{array}$ \\
\hline & $\begin{array}{l}\text { Telur } \\
\text { goreng iris }\end{array}$ & Telur ayam digoreng dengan diberi bumbu garam \\
\hline & Lalapan & $\begin{array}{l}\text { Lalapan yang digunakan ada Wortel iris, kacang panjang, } \\
\text { mentimun iris }\end{array}$ \\
\hline & $\begin{array}{l}\text { Daging } \\
\text { ayam } \\
\text { goreng }\end{array}$ & $\begin{array}{l}\text { Daging ayam direbus dengan bumbu bawang putih, kemiri } \\
\text { kunyit dan garam, kemudian ayam digoreng dengan diberi } \\
\text { tepung dan telur }\end{array}$ \\
\hline
\end{tabular}




\begin{tabular}{|c|c|c|}
\hline $\begin{array}{c}\text { Nama } \\
\text { Makanan }\end{array}$ & $\begin{array}{c}\text { Komponen } \\
\text { makanan }\end{array}$ & Bahan-bahan yang digunakan untuk membuat sajian \\
\hline & $\begin{array}{l}\text { Tempe } \\
\text { kering } \\
\text { kacang }\end{array}$ & $\begin{array}{l}\text { Tempe kedelai diiris kecil-kecil kemudian digoreng kering } \\
\text { dan dimasak dengan bumbu bawang merah, bawang putih } \\
\text { Jahe, daun jeruk purut, cabe merah, gula merah dan garam }\end{array}$ \\
\hline & Abon & $\begin{array}{l}\text { Ayam dimasak dengan bumbu bawang merah, bawang putih, } \\
\text { ketumbar, kemiri, daun jeruk purut, lengkuas, jahe, sereh, } \\
\text { santen kelapa, gula merah dan garam. Kemudian ayam yang } \\
\text { sudah dibumbui ditumbuk dan digoreng }\end{array}$ \\
\hline \multirow{7}{*}{$\begin{array}{l}\text { Tumpeng } \\
\text { putih }\end{array}$} & Nasi putih & Nasi yang dimasak dengan air \\
\hline & Telur rebus & Telur ayam direbus \\
\hline & Gudangan & $\begin{array}{l}\text { Sayur gudangan direbus menggunakan air yang mendidih. } \\
\text { Sayuran yang digunakan yaitu bayam, kangkung, kacang } \\
\text { panjang, toge, wortel, pepaya muda dan daun singkong. }\end{array}$ \\
\hline & $\begin{array}{l}\text { Bumbu } \\
\text { gudangan }\end{array}$ & $\begin{array}{l}\text { Kelapa diparut kemudian dimasak dengan bawang putih, } \\
\text { bawang merah, ketumbar, daun salam, daun jeruk purut, gula } \\
\text { merah dan garam }\end{array}$ \\
\hline & $\begin{array}{l}\text { Sambel } \\
\text { kacang } \\
\text { petek }\end{array}$ & $\begin{array}{l}\text { Sambel kacang petek dibuat dari kacang tolo dan ikan asin } \\
\text { petek yang digoreng. Kemudian kacang tolo dan ikan asin } \\
\text { petek ditumbuk dan diberi bumbu bawang putih, cabe rawit, } \\
\text { garam serta gula merah }\end{array}$ \\
\hline & $\begin{array}{l}\text { Sayur tempe } \\
\text { basah }\end{array}$ & $\begin{array}{l}\text { Tempe diiris dadu lalu dimasak dengan bumbu bawang } \\
\text { merah, bawang putih, daun salam, lengkuas, garam dan gula } \\
\text { merah }\end{array}$ \\
\hline & $\begin{array}{l}\text { Tancapan } \\
\text { cabe dan } \\
\text { bawang }\end{array}$ & Cabe rawit merah dan bawang merah \\
\hline \multirow[t]{9}{*}{$\begin{array}{l}\text { Tukon } \\
\text { pasar }\end{array}$} & $\begin{array}{ll}\text { Ubi jalar } \\
\text { rebus }\end{array}$ & Ubi jalar kuning direbus dengan air mendidih \\
\hline & $\begin{array}{l}\text { Singkong } \\
\text { rebus }\end{array}$ & $\begin{array}{l}\text { Singkong dikupas dari kulitnya kemudian dipotong lalu } \\
\text { direbus dengan air mendidih }\end{array}$ \\
\hline & $\begin{array}{l}\text { Wajik } \\
\text { merah dan } \\
\text { coklat }\end{array}$ & $\begin{array}{l}\text { Wajik dibuat dari beras ketan dengan diberi bahan lain seperti } \\
\text { santan kelapa, daun pandan, sirup (pewarna merah), gula } \\
\text { merah (pewarna coklat) dan garam }\end{array}$ \\
\hline & $\begin{array}{l}\text { Ketan } \\
\text { jaddah }\end{array}$ & $\begin{array}{l}\text { Ketan jaddah dibuat dari ketan yang ditumbuk dan diberi } \\
\text { kelapa parut serta garam secukupnya }\end{array}$ \\
\hline & $\begin{array}{l}\text { Jenang } \\
\text { merah }\end{array}$ & $\begin{array}{l}\text { Jenang terbuat dari tepung ketan yang dimasak dengan santan } \\
\text { kelapa, gula merah dan garam }\end{array}$ \\
\hline & Tawonan & $\begin{array}{l}\text { Tawonan dibuat dari tepung beras, kelapa, garam dan gula } \\
\text { merah }\end{array}$ \\
\hline & $\begin{array}{l}\text { Kacang } \\
\text { rebur }\end{array}$ & Kacang tanah direbus dengan air \\
\hline & Sawo & - \\
\hline & Jeruk & - \\
\hline
\end{tabular}




\begin{tabular}{lll}
\hline \multicolumn{1}{c}{$\begin{array}{c}\text { Nama } \\
\text { Makanan }\end{array}$} & $\begin{array}{c}\text { Komponen } \\
\text { makanan }\end{array}$ & \multicolumn{1}{c}{ Bahan-bahan yang digunakan untuk membuat sajian } \\
\hline & Bengkuang & - \\
\cline { 2 - 3 } & Apel & - \\
\cline { 2 - 3 } & Salak & - \\
\hline $\begin{array}{l}\text { Nasi } \\
\text { golong } \\
\text { gilig }\end{array}$ & Nasi putih & $\begin{array}{l}\text { Nasi putih dibentuk bundar seperti bola, kemudian dibungkus } \\
\text { dengan daun pisang klutuk. }\end{array}$ \\
\hline $\begin{array}{l}\text { Pisang } \\
\text { sanggan }\end{array}$ & $\begin{array}{l}\text { Pisang raja } \\
\text { yang sudah } \\
\text { masak }\end{array}$ \\
\hline
\end{tabular}

Berdasarkan hasil wawancara mendalam sajian yang dibuat dalam Tradisi Kuthomoro memiliki makna filosofi tersendiri yaitu sebagai berikut:

1 Sekul suci ulam sari adalah nasi dan lauk ayam ingkung. Berdasarkan hasil penelitian kata sekul suci memiliki arti nasi uduk/nasi gurih, sedangkan ulam sari ialah ayam ingkung. Hal ini sesuai dengan yang diungkapkan Puspita (2018) bahwa sekul suci ulam sari adalah nasi dan lauk yang biasanya berupa ayam yang harus dimasak oleh wanita dalam keadaan suci. Sekul suci ulam sari disajikan dalam selamatan bertujuan untuk sedekah kepada sesama manusia dan untuk mengirimkan doa yang ditujukan kepada Nabi Muhammad SAW dan leluhur yang memiliki hajat.

2 Wajik mengandung makna wajibnya anak mendoakan orang tua yang sudah wafat.

3 Ketan berasal dari kata khathaan yang artinya kesalahan. Kolak dari kata qola yang artinya mengucap. Apem berasal dari kata afuwun yang artinya ampunan. Berdasarkan dari hasil penelitian tiga serangkaian makanan ketan, kolak dan apem memiliki makna yaitu memohon semoga kesalahan yang lalu diampuni oleh Allah SWT. Hal ini sesuai dengan yang diungkapkan Bangunjiwo (2019) bahwa ketan, kolak dan apem memiliki makna bila ada kesalahan mohon untuk dimaafatkan atau diampuni.

4 Tumpeng kuning pada Tradisi Kuthomoro di Makam Giriloyo hanya digunakan sebagai tumpeng pelengkap. Bentuk tumpeng identik dengan kerucut yang bagian bawah lebar dan bagian atas kecil yang berarti manusia bermacam-macam, diharapkan bertindak secara lurus dan benar serta mengarah kepada Allah SWT. Hal ini sesuai dengan yang diungkapkan oleh Bangunjiwo (2019) bahwa tumpeng 
merupakan lantunan doa dan harapan yang bermakna bahwa manusia harus mampu bertindak secara lurus benar dan tepat serta mengarah kepada jalan Tuhan.

5 Tumpeng putih atau biasanya dapat disebut tumpeng gudangan/sayuran mengandung makna bahwa bermacam-macam manusia disatukan dengan pedoman supaya rukun, bertujuan untuk ingat kepada Allah SWT dan orang tua. Gudangan yang digunakan terdapat 7 macam jenis sayuran yang berbeda-beda. Makna 7 dari bahasa Jawa yaitu pitu yang berarti pitulung dari Allah atau pertolongan dari Allah yang berarti sebagai meminta pertolongan dalam segala hal. Hal ini sesuai yang diungkapkan Achmad (2019) bahwa angka 7 merupakan simbol harapan untuk mendapatkan pertolongan dari Tuhan. Bagian atas tumpeng putih terdapat cabe merah dan bawang merah dimaknai seperti lilin yang berfungsi sebagai penerangan. Hal ini sesuai dengan yang diungkapkan Dewantoro (2018) bahwa cabe merah di ujung tumpeng merupakan simbol dilah atau nyala api memberikan penerangan yang bermanfaatan bagi manusia lain.

Tumpeng tersebut di bedah di pendopo Masjid Makam Giriloyo yang bertujuan untuk memakmurkan masjid. Bedah tumpeng ini harus dilakukan dengan menyisir tumpeng tersebut dari pinggir ke tengah. Hal ini sesuai dengan yang diungkapkan Bangunjiwo (2019) bahwa tumpeng merupakan lambang kehidupan, maka seharusnya dibedah bukan dipotong. Membedah tumpeng berarti membedah makna tumpeng yang disajikan sebagai pelambang kehidupan manusia yang dinamis dan penuh arti.

6 Nasi golong gilig dalam Tradisi Kuthomoro di Makam Giriloyo merupakan makanan yang terbuat dari nasi putih dibentuk bundar seperti bola yang mengandung makna manteb/sudah klop sehingga bundar, yang berarti sudah mantab dalam berbakti kepada para leluhur. Hal ini sesuai dengan yang diungkapkan Yahya (2019) bahwa sego golong merupakan nasi putih yang di bentuk bulat seperti bola yang melambangkan kebulatan tekad yang manunggal.

7 Tukon pasar berisi macam-macam dari hasil bumi yang menunjukkan kemakmuran masyarakat. Tukon pasar pada Tradisi Kuthomoro di Makam Giriloyo memiliki makna sebagai penghormatan rasa syukur atas hasil bumi yang telah diberikan oleh 
Allah SWT. Hal ini sesuai dengan yang diungkapan Nurhayati, Mulyana, Ekowati, \& Meilawati (2014) bahwa makna tukon pasar ialah untuk mengucapkan rasa syukur kepada sang pencipta atas semua kebaikan yang telah dilimpahkan dan sebagai permohonan doa kepada sang pencipta untuk keselamatan dan kelancaran hidup. Tukon pasar adalah sesaji yang rangkaian unsurnya terdiri dari jajan pasar, buahbuahan dan olahan hasil bumi.

8 Pisang sanggan harus menggunakan pisang raja karena melambangkan suatu harapan agar kelak seorang hidupnya dapat berbuat mulia, agung serta berguna seperti seorang raja (Hadisutrisno, 2009). Pisang sanggan pada tradisi Kuthomoro di Makam Giriloyo terdiri dari dua sisir pisang raja yang sudah matang dalam satu tampah, yang mengandung makna supaya manusia mampu menyanggah hidup. Pisang sanggan harus terdiri dari dua sisir supaya dalam menyanggah hidup seimbang.

9 Kelapa gula dalam Tradisi Kuthomoro di Makam Giriloyo memiliki makna sebagai nyawijekake asale podo ning bentukke bedo-bedo, yang berarti manusia itu asalnya sama dari Allah SWT namun memiliki kemampuan yang berbeda-beda antara manusia lainnya.

\section{Analisis potensi hasil penelitian sebagai sumber belajar biologi materi tumbuhan SMA Kelas X pada Kurikulum 2013}

Proses belajar mengajar yang dilakukan dikelas pada mata pelajaran IPA khususnya Biologi harus mewujudkan interaksi antara peserta didik dengan materi pembelajaran biologi agar tujuan pembelajaran yang diinginkan dapat tercapai. Hasil penelitian dapat digunakan sebagai sumber belajar harus melalui beberapa tahapan-tahapan diantaranya identifikasi proses dan hasil penelitian serta seleksi dan modifikasi hasil penelitian sebagai sumber belajar biologi. Pelaksanaan proses penelitian menghasilkan fakta-fakta yang selanjutnya menjadi konsep-konsep dan prinsip-prinsip yang merupakan laporan hasil penelitian. Laporan penelitian tersebut selanjutnya berlaku dan memenuhi persyaratan sebagai sumber belajar. Persyaratan sumber belajar tersebut menggunakan prinsip Suhardi (2012) meliputi kejelasan potensi ketersediaan objek dan permasalahan yang diangkat, Kejelasan kesesuaian dengan tujuan pembelajaran, kejelasan sasaran materi dan peruntukannya, kejelasan 
informasi yang akan diungkan, kejelasan Pedoman eksplorasi, kejelasan perolehan yang akan dicapai.

Hasil penelitian di analisis berdasarkan syarat-syarat sumber belajar menurut Suhardi (2012). Berdasarkan analisis yang telah dilakukan hasil penelitian berpotensi sebagai sumber belajar biologi SMA kelas X Kompetensi Dasar 3.8 yang mengacu kepada kurikulum 2013 khususnya pada materi tumbuhan divisi Spermatophyta. Hasil penelitian akan dikembangkan menjadi media pembelajaran berupa infografis untuk mempermudah siswa dalam memahami materi. Infografis yang dibuat berupa penyajian informasi mengenai tumbuhan dan sajian yang memiliki makna simbolik dalam Tradisi Kuthomoro di Makam Giriloyo. Menurut Kustandi \& Sutjipto (2011) media pembelajaran merupakan alat yang dapat membantu proses pembelajaran dan berfungsi untuk memperjelas makna pesan yang disampaikan sehingga dapat mencapai tujuan pembelajaran dengan lebih baik dan sempurna.

\section{SIMPULAN}

Berdasarkan penelitian yang telah dilakukan mengenai Analisis Potensi Hasil Penelitian Etnobotani Tradisi Kuthomoro di Makam Giriloyo Imogiri Bantul Yogyakarta sebagai Sumber Belajar Biologi SMA Kelas X Materi Tumbuhan dapat disimpulkan bahwa tumbuhan yang digunakan pada tradisi Kuthomoro ada 44 jenis tumbuhan. Makna simbolik dari tumbuhan yang digunakan pada tradisi Kuthomoro di Makam Giriloyo merupakan sebuah doa dan harapan baik semoga kesalahan para leluhur dimaafkan dan diberi tempat yang lebih baik oleh Allah SWT. Hasil penelitian Etnobotani Tradisi Kuthomoro di Makam Giriloyo Imogiri Bantul Yogyakarta dapat dijadikan sebagai sumber belajar pada materi tumbuhan pada divisi Spermatophyta.

\section{DAFTAR PUSTAKA}

Achmad, S. W. (2019). Sejarah Agama Jawa. Yogyakarta: Araska.

Arisandi, D. H. (2013). Tradisi Adzan Tumbal di Dusun Giriloyo Desa Wukirsari Kecamatan Imogiri Kabupaten Bantul YogyakartaTradisi Adzan Tumbal di Dusun Giriloyo Desa Wukirsari Kecamatan Imogiri Kabupaten Bantul Yogyakarta. In Skripsi. Yogyakarta: UIN Sunan Kalijaga.

Bangunjiwo, K. J. (2019). Tata Cara Pengantin Jawa. Yogyakarta: Narasi.

Dewantoro, S. H. (2018). Sastrajendra (Ilmu Kesempuraan Jiwa). Banten: Javanica.

Hadisutrisno, B. (2009). Islam Kejawen. Yogyakarta: Eule Book. 
Kustandi, C., \& Sutjipto, B. (2011). Media Pembelajaran. Bogor: Ghalia Indonesia.

Ningsih, E. (2012). Nilai Nilai Pendidikan Islam dalam Tradisi Rasulan di Desa Giriloyo, Wukirsari, Imogiri, Bantul. In Skripsi. Yogyakarta: Fakultas Tarbiyah dan Keguruan UIN Sunan Kalijaga.

Nurhayati, E., Mulyana, M., Ekowati, I. V., \& Meilawati, A. (2014). Inventarisasi Makanan Tradisional Jawa Unsur Sesaji di Pasar-Pasar Tradisional Kabupaten Bantul. Jurnal Penelitian Humaniora, 19(2), 124-140. Diunduh dari https://journal.uny.ac.id/index.php/humaniora/article/view/8039.

Peraturan Daerah Provinsi Daerah Istimewa Yogyakarta nomor 5 Tahun 2011 tentang Pengelolaan dan Penyelenggaraan Pendidikan Berbasis Budaya. (n.d.).

Pranoto, T. H. T. (2009). Tata Upacara Adat Jawa. Yogyakarta: Kuntul Press.

Puspita, A. R. (2018). Refleksi Kepercayaan Masyarakat Pesisir Pantai Prigi dalam Sajen Slametan Njangkar (Kajian Etnolinguistik). Jurnal Masyarakat \& Budaya, 20(2), 261-272. Diunduh dari https://jmb.lipi.go.id/jmb/article/view/614.

Rusli, M. S. (2010). Sukses Memproduksi Minyak Atsiri. Yogyakarta: Andi offset.

Suhardi, S. (2012). Pengembangan Sumber Belajar Biologi. Yogyakarta: UNY Press.

Sukmadinata, N. S. (2009). Metode Penelitian Pendidikan Kuantitatif, Kualitatif, PTK, R\&D. Surakarta: Fairuz Media.

Supinah, P. (2006). Sawer: Komunikasi Simbolik pada Adat Tradisi Suku Sunda dalam Upacara Setelah Perkawinan. Mediator: Jurnal Komunikasi, 7(1), 85-94. Diunduh dari https://ejournal.unisba.ac.id/index.php/mediator/article/view/1225.

Yahya, M. I. (2019). Tradisi Sedekah Laut Masyarakat Desa Labuhan Kecamatan Brondong Kabupaten Lamongan Tahun 1990-2015. Avatara: E-Journal Pendidikan Sejarah, $7(1)$.

Diunduh

dari https://jurnalmahasiswa.unesa.ac.id/index.php/avatara/article/view/26710\#: :text=R itual\%20sedekah\%20laut\%20adalah\%20salah,kesimbangan\%20lingkungan\%20pesi sir\%20pantai\%20serta. 